ORIGINAL ARTICLE

\title{
Crisis management during anaesthesia: the development of an anaesthetic crisis management manual
}

\author{
W B Runciman, M T Kluger, R W Morris, A D Paix, L M Watterson, R K Webb
}

Qual Saf Health Care 2005;14:e1 (http://www.qshc.com/cgi/content/full/14/3/el). doi: 10.1136/qshc.2002.004101

See end of article for authors' affiliations

.....................

Correspondence to: Professor W B Runciman, President, Australian Patient Safety Foundation, GPO Box 400, Adelaide, South Australia 5001 Australia; research@apsf. net.au

Accepted 10 January 2005
Background: All anaesthetists have to handle life threatening crises with little or no warning. However, some cognitive strategies and work practices that are appropriate for speed and efficiency under normal circumstances may become maladaptive in a crisis. It was judged in a previous study that the use of a structured "core" algorithm (based on the mnemonic COVER ABCD-A SWIFT CHECK) would diagnose and correct the problem in $60 \%$ of cases and provide a functional diagnosis in virtually all of the remaining $40 \%$. It was recommended that specific sub-algorithms be developed for managing the problems underlying the remaining $40 \%$ of crises and assembled in an easy-to-use manual. Sub-algorithms were therefore developed for these problems so that they could be checked for applicability and validity against the first 4000 anaesthesia incidents reported to the Australian Incident Monitoring Study (AIMS).

Methods: The need for 24 specific sub-algorithms was identified. Teams of practising anaesthetists were assembled and sets of incidents relevant to each sub-algorithm were identified from the first 4000 reported to AIMS. Based largely on successful strategies identified in these reports, a set of 24 specific subalgorithms was developed for trial against the 4000 AIMS reports and assembled into an easy-to-use manual. A process was developed for applying each component of the core algorithm COVER at one of four levels (scan-check-alert/ready-emergency) according to the degree of perceived urgency, and incorporated into the manual. The manual was disseminated at a World Congress and feedback was obtained.

Results: Each of the 24 specific crisis management sub-algorithms was tested against the relevant incidents among the first 4000 reported to AIMS and compared with the actual management by the anaesthetist at the time. It was judged that, if the core algorithm had been correctly applied, the appropriate subalgorithm would have been resolved better and/or faster in one in eight of all incidents, and would have been unlikely to have caused harm to any patient. The descriptions of the validation of each of the 24 subalgorithms constitute the remaining 24 papers in this set. Feedback from five meetings each attended by 60-100 anaesthetists was then collated and is included.

Conclusion: The 24 sub-algorithms developed form the basis for developing a rational evidence-based approach to crisis management during anaesthesia. The COVER component has been found to be satisfactory in real life resuscitation situations and the sub-algorithms have been used successfully for several years. It would now be desirable for carefully designed simulator based studies, using naive trainees at the start of their training, to systematically examine the merits and demerits of various aspects of the sub-algorithms. It would seem prudent that these sub-algorithms be regarded, for the moment, as decision aids to support and back up clinicians' natural responses to a crisis when all is not progressing as expected.
A Il anaesthetists have to manage life threatening crises which may arise with little or no warning. ${ }^{1-4}$ Indeed, with a risky procedure in a sick patient, much of the working day may be spent preventing and heading off potential crises. Anaesthetists manage the vast majority of these complex problems promptly and efficiently with skilled pattern recognition and frequently practised clinical routines. However, high profile cases documented in the lay press from around the world indicate that these patterns of response do not always lead to the resolution of problems. ${ }^{5}$ Attention has been focused worldwide on the safety of health care and the ways in which it may be enhanced. Working groups from several countries including the USA, ${ }^{6} \mathrm{UK}^{7}$ and Australia ${ }^{8}$ have produced documents outlining plans for improving the safety of health care. This set of 25 articles outlines a structured approach for when things are going wrong during anaesthesia..$^{9-32}$ Prevention is, of course, better than cure. However, prevention (for example, appropriate preoperative assessment, checking and planning) is not the intent of this set of articles.
As indicated above, situations do arise during which patient safety is compromised when the usual measures have been or are being taken. This is the context in which an incident report may be submitted. The Australian Incident Monitoring Study (AIMS) was started in $1988 .{ }^{33}$ In 1993 a symposium issue reviewing the first 2000 incidents was published in the journal Anaesthesia and Intensive Care. ${ }^{34}$ The symposium consisted of 30 papers looking at various aspects of anaesthetic incidents. These included clinical crises and adverse events (such as anaphylaxis, difficult intubation, cardiac arrest, the wrong drug problem), assessments of the applications and limitations of physiological monitors (for example, the pulse oximeter, the electrocardiograph, the capnograph), and an evaluation of the factors involved in the generation and resolution of these incidents. In seven out of every eight incidents which arose when patients were breathing gas from an anaesthetic machine, the anaesthetists involved recognised the problem and responded appropriately. ${ }^{4}$ However, in one out of every eight it was considered by an AIMS panel of reviewers that the application of a simple 
learned routine, properly applied, would have expedited the diagnosis and/or led to an appropriate response more rapidly-and often more effectively. ${ }^{4}$ This is because previously learned and intuitive strategies and work practices which have evolved for speed and efficiency under normal working conditions may fail to adjust in a crisis. ${ }^{35}$ Use of such "pre-compiled responses" is consistent with the "rapid phase" learned responses to some crises in aviation, nuclear plant operation, community rescue organisations, and military command, many of which are routinely tested in simulation situations. ${ }^{2}$

These findings suggested that there is a place for defaulting to a simple structured routine when the anaesthetist is uneasy that all may not be what it seems to be, when the situation is deteriorating, or when an adverse outcome seems likely. It is well recognised within the field of human error and safety that the use of simple succinct guidelines and protocols reduces the burden on the individuals involved and allows their limited available cognitive resource to be used for essential immediate tasks. ${ }^{36}{ }^{37}$ Some of the principles underlying this structured approach have been dealt with in a companion paper. ${ }^{35}$

\section{THE "COVER-ABCD A SWIFT CHECK" CORE ALGORITHM}

After considering a number of alternatives, it was generally agreed after a series of three meetings, each attended by $60-$ 100 anaesthetists, that a "core" algorithm should form the basis for the management of any crisis in which the anaesthetist was uncertain of the exact cause or which was not going exactly as expected. ${ }^{4}$ A common starting sequence for all crises was thought to be essential because it was recognised that it is very difficult to recover from a "mind set" that a particular problem is being faced when, in fact, the problem is a different one requiring a completely different solution.

Such a core algorithm was devised based on the mnemonic "COVER ABCD-A SWIFT CHECK" which is suitable for use when any patient is undergoing general or regional anaesthesia. The original version, which was available on two sides of a single laminated sheet, is shown in tables 1 and 2. When the manual which resulted from this set of 25 articles was compiled, more detailed instructions were made available about aspects of this core algorithm (see figs 1 and 2). The use of the traditional cardiac arrest mnemonic "ABCD" was considered but it was thought that it would "miss" some dangerous problems related to the surgery, the use of the anaesthetic machine, and ancillary equipment which would require immediate resolution; this is discussed in the last section of this paper.

The initial component, COVER-which addresses problems arising from circulatory compromise, the gas supply, the anaesthetic machine, the breathing circuit, the ventilator and the endotracheal tube-has been validated against the 1301 relevant incidents under general anaesthesia amongst the first 2000 reported to AIMS. ${ }^{4}$ It was found that just under

Table 1 Crisis management algorithm - memorise and practise: an explanation of each cue in the mnemonic "COVER ABCD"

\begin{tabular}{|c|c|c|}
\hline $\mathrm{Cl}$ & Circulation & $\begin{array}{l}\text { Establish adequacy of peripheral circulation (rate, rhythm and character of pulse). If } \\
\text { pulseless, institute cardiopulmonary resuscitation (CPR). The core algorithm must still } \\
\text { be completed as soon as possible. }\end{array}$ \\
\hline $\mathrm{C} 2$ & Colour & $\begin{array}{l}\text { Note saturation. Examine for evidence of central cyanosis. Pulse oximetry is superior } \\
\text { to clinical detection and is recommended. Test probe on own finger, if necessary, } \\
\text { whilst proceeding with } \mathrm{O} 1 \text { and } \mathrm{O} 2 \text {. }\end{array}$ \\
\hline 01 & Oxygen & Check rotameter settings, ensure inspired mixture is not hypoxic. \\
\hline $\mathrm{O} 2$ & Oxygen analyser & $\begin{array}{l}\text { Adjust inspired oxygen concentration to } 100 \% \text { and note that only the oxygen } \\
\text { flowmeter is operating. Check that the oxygen analyser shows a rising oxygen } \\
\text { concentration distal to the common gas outlet. }\end{array}$ \\
\hline V1 & Ventilation & $\begin{array}{l}\text { Ventilate the lungs by hand to assess breathing circuit integrity, airway patency, chest } \\
\text { compliance and air entry by "feel" and careful observation and auscultation. Also } \\
\text { inspect capnography trace. }\end{array}$ \\
\hline V2 & Vaporiser & $\begin{array}{l}\text { Note settings and levels of agents. Check all vaporiser filler ports, seatings and } \\
\text { connections for liquid or gas leaks during pressurisation of the system. Consider the } \\
\text { possibility of the wrong agent being in the vaporiser. }\end{array}$ \\
\hline E1 & Endotracheal tube & $\begin{array}{l}\text { Systematically check the endotracheal tube (if in use). Ensure that it is patent with no } \\
\text { leaks or kinks or obstructions (see suggested protocol in Anaesth Intensive Care } \\
\text { 1993;21:615). Check capnograph for tracheal placement and oximeter for possible } \\
\text { endobronchial position. If necessary, adjust, deflate cuff, pass a catheter, or remove } \\
\text { and replace. }\end{array}$ \\
\hline E2 & Elimination & $\begin{array}{l}\text { Eliminate the anaesthetic machine and ventilate with self-inflating (e.g. Air Viva) bag } \\
\text { with } 100 \% \text { oxygen (from alternative source if necessary). Retain gas monitor sampling } \\
\text { port (but be aware of possible problems). }\end{array}$ \\
\hline R1 & Review monitors & $\begin{array}{l}\text { Review all monitors in use (preferably oxygen analyser, capnograph, oximeter, blood } \\
\text { pressure, electrocardiograph (ECG), temperature and neuromuscular junction } \\
\text { monitor). For proper use, the algorithm requires all monitors to have been correctly } \\
\text { sited, checked and calibrated. }\end{array}$ \\
\hline R2 & Review equipment & $\begin{array}{l}\text { Review all other equipment in contact with or relevant to the patient (e.g. diathermy, } \\
\text { humidifiers, heating blankets, endoscopes, probes, prostheses, retractors and other } \\
\text { appliances). }\end{array}$ \\
\hline A & Airway & $\begin{array}{l}\text { Check patency of the unintubated airway. Consider laryngospasm or presence of } \\
\text { foreign body, blood, gastric contents, nasopharyngeal or bronchial secretions. }\end{array}$ \\
\hline B & Breathing & $\begin{array}{l}\text { Assess pattern, adequacy and distribution of ventilation. Consider, examine and } \\
\text { auscultate for bronchospasm, pulmonary oedema, lobar collapse and pneumo- or } \\
\text { haemothorax. }\end{array}$ \\
\hline C & Circulation & $\begin{array}{l}\text { Repeat evaluation of peripheral perfusion, pulse, blood pressure, ECG and filling } \\
\text { pressures (where possible) and any possible obstruction to venous return, raised } \\
\text { intrathoracic pressure (e.g. inadvertent PEEP) or direct interference to (e.g. stimulation } \\
\text { by central line) or tamponade of the heart. Note any trends on records. }\end{array}$ \\
\hline D & Drugs & $\begin{array}{l}\text { Review intended (and consider possible unintended) drug or substance administration. } \\
\text { Consider whether the problem may be due to unexpected effect, a failure of } \\
\text { administration or wrong dose, route or manner of administration of an intended or } \\
\text { "wrong drug". Review all possible routes of drug administration. }\end{array}$ \\
\hline
\end{tabular}




$\begin{array}{cll}\text { Table } 2 & \text { "A SWIFT CHECK" (the checklist arising from the mnemonic need not be } \\ \text { memorised but should be immediately available in the operating theatre) }\end{array}$

$60 \%$ of these problems had arisen from these sources and that COVER, correctly applied, would have provided a functional diagnosis and an appropriate response in virtually all the cases in 40-60 seconds. ${ }^{4}$ Subsequent users and many case presentations at audits have confirmed that COVER can be rapidly performed and is reliable.

If the remainder of the algorithm had been used (ABCD-A SWIFT CHECK), it was considered that, correctly applied, a functional diagnosis would have been obtained in $99 \%$ of these incidents. However, unlike the COVER component, the ABCD-A SWIFT CHECK component is largely a diagnostic checklist. The anaesthetist would still have to handle the $40 \%$ of problems remaining after COVER-that is, those arising from the patient or from patient/doctor/procedure/drug interactions. To do this the anaesthetist may work from first principles, employ pattern recognition and learned sequences or, failing this, apply one of a set of prescribed subalgorithms. Experience from audits of anaesthetic practice and ongoing review of AIMS forms has confirmed that it would be desirable for there to be a basic set of structured sub-algorithms to handle the problems arising from these sources when the problem is not immediately resolved, as on many occasions the management described constitutes a considerable departure from what would generally be regarded as currently accepted practice. The development of the 24 sub-algorithms deemed necessary is described in the other articles in this series as shown in table $3 .^{9-32}$

How this was done is presented below. However, first, the issue of how to use the "COVER" component of the core algorithm is discussed in more detail.

\section{HOW TO USE "COVER"}

An important issue to arise from discussions about the core algorithm was the question as to when and how it should be invoked. The majority of potential incidents are recognised early in their evolution and are "headed off" by appropriate responses on the part of the anaesthetist. Of those events that actually moved an anaesthetist to fill in an incident report, seven out of eight were correctly recognised and promptly handled; for these, pattern recognition was clearly successful and the use of COVER was unnecessary, and would potentially have been more time consuming and disruptive than the initial response.

How should the anaesthetist recognise when the situation justifies invoking the full set of actions required by COVER? ${ }^{4}$ It is obvious, for example, that it is not worth getting rid of the anaesthetic machine when the saturation falls from $98 \%$ to $94 \%$ over 10 minutes. However, it is equally obvious that COVER should be invoked in full if a patient is suddenly found pulseless and cyanosed with slow wide QRS complexes on the electrocardiogram.

\section{"SCARE"}

A solution to this problem lies in grading the application of each component of COVER into four levels represented by the mnemonic "SCARE", depending on the degree of perceived urgency (Scan-Check-Alert/Ready-Emergency). These are shown in figs 3-6.

The various levels of each component of COVER should be used in combinations deemed appropriate for the situation. This provides great flexibility and appropriateness of response 


\section{WHEN AND HOW TO USE THIS MANUAL}

The manual is based on the mnemonic "COVER ABCD-A SWIFT CHECK" and is designed for use when any patient is undergoing general or regional anaesthesia. The sequence becomes $A B$ COVER CD-A SWIFT CHECK when the patient is breathing spontaneously, and some components become redundant in certain circumstances; examples are given at the end of this section.

The mnemonic serves as a reminder to always cycle systematically through a basic series of thoughts and actions, the intensity of which will depend on the circumstances. This series of thoughts and actions is:

\section{Circulation, Capnograph, and Colour (saturation) \\ O Oxygen supply and Oxygen analyser \\ V Ventilation (intubated patient) and Vaporisers \\ E Endotracheal tube and Eliminate machine \\ R Review monitors and Review equipment}

A Airway (with face or laryngeal mask)

B Breathing (with spontaneous ventilation)

D Drugs (consider all given or not given)

A Be Aware of Air and Allergy - page 4*

SWIFT CHECK of patient, surgeon, process, and responses.

The four levels of intensity for each of these components are represented by another mnemonic - "SCARE" (SCAN, CHECK, ALERT/READY, EMERGENCY) and comprise pages 4 to $11^{*}$ of this manual.

The SCAN sequence should be followed every 5 minutes of any anaesthetic, or more often if necessary. This overcomes the need for special training sessions, as the sequence rapidly becomes second nature and can usually be completed in $40-60$ seconds. The CHECK sequence should be used whenever all is not going according to plan, and should also be practised regularly.

Do not hesitate to move on to the ALERT/READY and EMERGENCY sequences if you are worried, if events are moving quickly, or if it seems that an adverse outcome is possible. These should also be practised from time to time.

*Page references refer to the Crisis Management Manual. ${ }^{38}$
Depending on the circumstances, components of each level of SCARE may be assembled as appropriate, as long as the sequence of COVER is always adhered to. For example, with sudden, severe hypertension, if the first four components of COVER (Circulation, Colour, Oxygen, Oxygen Analyser) are stable and normal at the SCAN level, no further action is required for these. However, it would be desirable to use the CHECK level for the Ventilation,

Vaporiser, Review monitors, and Review equipment components of COVER, for the C (Circulation) and D (Drugs) components of $A B C D$, for the A (for Awareness) and for SWIFT CHECK (especially with respect to what the surgeon is doing). Hypertension and awareness are two circumstances in which the concentration of volatile agent may be increased - for most crises it is left alone at the SCAN and CHECK levels and turned off at the READY/ALERT and EMERGENCY levels.

On the other hand, if, for example, it is suddenly noticed that the patient is pulseless and blue, the full EMERGENCY sequence of COVER should be carried out immediately with progression to any appropriate sub-algorithms.

It is important that the basic COVER ABCD sequence is followed before becoming focused on any particular sub-algorithm; a major problem is "locking onto" a diagnosis which may not be correct. When assistance is called for, one person should repeatedly cycle through the COVER ABCD sequence and consider other possibilities, whilst the steps in any relevant sub-algorithms are followed. Some sub-algorithms repeat components of COVER (e.g. "give 100\% oxygen"), usually when the entire sequence does not necessarily have to be followed in full at the outset, whereas others start by instructing anaesthesiologists to ensure that the full COVER sequence has been completed before starting the sub-algorithm (e.g. that for persistent desaturation, or air embolism).

Although the standard COVER ABCD-A SWIFT CHECK sequence should always be followed, some components become less important or redundant under particular circumstances: for intubated, ventilated patients the $\mathbf{A}$ and $\mathbf{B}$ after COVER become redundant; for patients breathing spontaneously via a mask, $\mathbf{A}$ and $\mathbf{B}$ precede COVER, as indicated at the start of this section, and $\mathbf{V}$ for Ventilation becomes redundant; for a patient being ventilated via a laryngeal mask, B becomes redundant; and for a patient breathing spontaneously and receiving oxygen from a source independent of an anaesthetic machine (e.g. from a wall mounted flowmeter during regional or intravenous anaesthesia), the $\mathbf{V}$ and $\mathbf{E}$ of COVER become redundant.

Figure 1 Introduction to the Crisis Management Manual.

while still reducing the cognitive load for the anaesthetist. It can be argued that COVER is no longer an algorithm when different actions can be taken, depending on circumstances, and that it should more properly be called a "cognitive aid", encouraging the use of various "pre-compiled responses". However, for the sake of simplicity, we will continue to use the term algorithm for this set of articles.

The use of the SCAN level every 5 minutes during each case (fig 3 ) and of the CHECK level at regular intervals (fig 4) also overcomes the problem of regular formal training being required for the effective use of the core crisis management algorithm. Commercial jet airline pilots are required to undertake simulator sessions and be accredited every 3 months. However, to introduce this for every practising anaesthetist, whilst desirable, is not feasible at the moment, especially in developing countries.

In general, the slower and less serious the deviations from normal and the more monitoring and other information available, the less likely it will be that the EMERGENCY mode of COVER will need to be used. However, in circumstances in which the situation is obscure or not readily apparent due to opaque or non-specific signs, or is progressing rapidly, there should be no hesitation in invoking the algorithm to the full. In contexts in which no monitors are available, it is likely that the full application of the EMERGENCY mode of COVER would be much more frequently invoked. ${ }^{39}$

For those who have practised using COVER in this way, appropriate responses may rapidly be achieved while the anaesthetist is confident that the majority of possible contingencies have been accounted for. This knowledge is valuable for trainees who have not yet fully developed their pattern recognition and clinical response routines, for any anaesthetist who encounters a novel situation, when all is not going well, or when there is likely to be an adverse outcome. In this last context, the anaesthetist can proceed with handling the problem to the best of his or her ability, taking some comfort in the knowledge that any independent 


\section{SOME FINAL TIPS}

REMEMBER: Always go through COVER ABCD for ventilated patients and $A B$ COVER CD for spontaneously breathing patientsfollowed in each instance by A SWIFT CHECK. It will be obvious in any particular circumstance which components become redundant.

REMEMBER: Request assistance early on, allocate tasks and calmly coordinate activities, repeatedly cycling through COVER as well as any sub-algorithm/s thought to be appropriate.

\section{REGIONAL ANAESTHESIA}

There are two differences with regional anaesthesia.

1 At the $\mathbf{A}$ for Awareness stage of $\mathbf{A}$ SWIFT CHECK: if the patient is sedated or conscious, talk to the patient, and, if concerned, ask how they are feeling.

2 At the CHECK level of A SWIFT CHECK: check the quality and extent of any block, and correlate the estimated extent of sympathetic blockade with any cardiovascular sequelae.

\section{ABBREVIATIONS:}

$\begin{array}{lll}\text { Monitors } & & \\ \mathrm{ETCO}_{2} & - & \text { End tidal carbon dioxide concentration } \\ \mathrm{FIO}_{2} & - & \text { Oxygen fraction of the inspired gas } \\ \mathrm{SpO}_{2} & - & \text { Pulse oximeter saturation readout } \\ \mathrm{BP} & - & \text { Blood pressure } \\ \mathrm{ECG} & - & \text { Electrocardiogram } \\ \text { Circulation } & & \\ \text { VF } & - & \text { Ventricular fibrillation } \\ \text { VT } & - & \text { Ventricular tachycardia } \\ \text { Airway } & & \\ \text { ETT } & - & \text { Endotracheal tube } \\ \text { LMA } & - & \text { Laryngeal mask airway } \\ \text { Breathing } & & \\ \text { IPPV } & - & \text { Intermittent positive pressure ventilation } \\ \text { PEEP } & - & \text { Positive and expiratory pressure } \\ \text { CPAP } & - & \text { Continuous positive airway pressure } \\ \text { ARDS } & - & \text { Adult respiratory distress syndrome. }\end{array}$

LAYOUT OF THE MANUAL: The immediate sequences of thoughts and actions are shown on the right hand pages. References to ongoing care and further details are on the reverse sides of these pages. This will allow single pages to be replaced as sub-algorithms are updated.

Figure 2 Final instructions and abbreviations for the Crisis Management Manual.

retrospective review must find that the appropriate responses had been made for over $99 \%$ of the spectrum of problems reported to AIMS.

The SCARE algorithms have been incorporated into the Crisis Management Manual developed from this set of 25 articles. ${ }^{38}$ There has been considerable feedback that the use of this SCARE-based graded response has proved to be quite satisfactory for those who have decided to use the manual as it is. However, the concept of using such a highly structured graded response does not have universal acceptance. Some prefer to remember the COVER algorithm only for emergency use when pattern recognition appears to have failed. Also, while the SCAN routine of the COVER mnemonic is perfectly satisfactory, some clinicians prefer their own "SCAN" routine based on local circumstances and their own equipment setup.

It is recognised that complexity can cause errors ${ }^{13}$ and that reducing choice, reducing the number of steps required, and ensuring that the duration of execution is as short as possible all assist in reducing the complexity of a system. However, this should not be at the cost of ensuring safety. There is a trade-off between relying on pattern recognition and using the highly structured approach represented in the Crisis

\section{Table 3 Papers in Crisis Management series}

A Obstruction of the natural airway

A Laryngospasm ${ }^{10}$

A Regurgitation, vomiting and aspiration"

A Difficult intubation ${ }^{12}$

B Desaturation ${ }^{13}$

B Bronchospasm ${ }^{14}$

B Pulmonary oedema ${ }^{15}$

C Bradycardia ${ }^{16}$

C Tachycardia $^{17}$

C Hypotension ${ }^{18}$

C Hypertension'

C Myocardial ischaemia ${ }^{20}$

C Cardiac arrest ${ }^{21}$

D Problems associated with drug administration during anaesthesia ${ }^{22}$

A Awareness ${ }^{23}$

A Embolism ${ }^{24}$

A Pneumothorax ${ }^{25}$

A Anaphylaxis and allergy ${ }^{26}$

Vascular access problems ${ }^{27}$

Trauma: development of a sub-algorithm ${ }^{28}$

Sepsis ${ }^{29}$

Water intoxication ${ }^{30}$

Crisis management during regional anaesthesia ${ }^{3}$

Recovering from a crisis $^{32}$

The 24 sub-algorithms are described in this set of articles. These are represented by ABCD (A - Airway; B - Breathing; C - Circulation; D Drugs), A (the four As - be Aware of Air (embolism or in the pleura) and Allergy), SWIFT CHECK ("miscellaneous problems such as vascular access problems, trauma, sepsis, water intoxication, problems arising during regional anaesthesia, and recovering from a crisis). Additional problems such as endocrine, electrolyte and metabolic problems (including malignant hyperthermia) are also dealt with in the manual.

Management Manual by the SCARE sequence. The challenge is to cover all contingencies while retaining as simple a set of responses as possible. It is likely that COVER will be refined with more use; there are advantages to defaulting to a standard sequence of actions when people have to work in teams in a crisis. ${ }^{36}$

\section{"ABCD-A SWIFT CHECK"}

The rationale for the use of sub-algorithms for the ABCD-A SWIFT CHECK portion of the mnemonic is the same as that which underpins the use of the core algorithm for the first part (COVER). Complex problems may be manifested by nonspecific cues in circumstances in which a minor transgression or a delay in taking corrective measures might have serious consequences. For example, of 179 incidents first detected by oximetry and thus having manifested as desaturation, just under three quarters (represented by nine "clinical situations" including dangerous problems requiring rapid resolution such as hypoxic gas mixture and undetected oesophageal intubation) were handled by COVER. ${ }^{4}{ }^{39}{ }^{40}$ However, over one quarter fell into the ABCD-A SWIFT CHECK portion of the algorithm. These were represented by 12 "clinical situations", some of which had relatively rare or obscure causes but required rapid diagnosis and a prompt response-for example, anaphylaxis, air embolism, tension pneumothorax, pulmonary oedema. In some of these cases the correct diagnosis was "missed" for a prolonged time. With such an array of possibilities it is too time consuming to work from first principles. In such circumstances, if the problem is not resolved immediately by actions based on pattern recognition, the use of a carefully validated prescribed algorithm is safer and more reliable than trying to work out what the problem is, and what to do about it, from first principles.

Early on, a number of anaesthetists commented that they found the use of A SWIFT CHECK as a mnemonic, as shown in table 2, to be contrived and unhelpful. It was therefore replaced as follows. Firstly, the sentence "Be Aware of Air and Allergy" was suggested as a reminder for what the As in 


\section{The column on the left lists, in the order of the mnemonic, what should be "scanned". This will comprise a "facing" page of the manual. Notes corresponding to the numbers in parentheses will be on the reverse side.}

\section{SCAN as needed, or every 5 minutes}

Circulation: Note the rate, rhythm and volume of the pulse and note the end tidal carbon dioxide concentration $\left(\mathrm{ETCO}_{2}\right)(1)^{*}$.

Colour: Note the colour of the patient's mucous membranes and blood and note the saturation reading of the oximeter $\left(\mathrm{SpO}_{2}\right)$.

Oxygen: Note the rotameter settings and that the bobbins are spinning and calculate the inspired oxygen fraction $\left(\mathrm{FIO}_{2}\right)(2)$.

Oxygen Analyser: Note that the readout matches that expected in the inspiratory limb of the breathing circuit. Calibrate if necessary.

Ventilation: Note the patient's chest movements. Correlate these with the capnograph, breathing circuit pressures and tidal volumes.

Vaporisers: Note the vaporiser settings on all vaporisers and the volatile agent liquid level on the vaporiser in use.

Endotracheal tube or laryngeal mask airway: Note its position (distance marker at the lips), its orientation and its security (3).

Eliminate: Note that, in a crisis, you may need to remove machine, circuit, filter, ETT and its connections, e.g. the "catheter mount".

Review monitors: Note monitors in use and review all readings, waveforms and alarm settings. Update the anaesthetic record (4).

Review equipment: Note all equipment in use, especially items in contact with the patient. Review its safety and function (5).

Airway: Note the position of the head and neck, and the position, patency and security of any artificial airways or masks (6).

Breathing: Note chest and abdominal movements and correlate these with the respiratory rate and pattern of spontaneous ventilation.

Circulation: Note trends in all cardiovascular parameters and correlate these with estimated blood or other fluid loses (7).

Drugs: Note drugs that have been given and correlate doses with effects. Note correct function of all IV lines and infusions (8).

A: "Be Aware of Air and Allergy". Be Aware yourself, think of possible Awareness in the patient, and of Air (or other) embolism, Air in the pleura (pneumothorax), Allergy or Anaphylaxis (9).

SWIFT CHECK: Note what the surgeon and other personnel are doing, check the patient's position on the table and that the physiological responses match the circumstances.

*Numbers in brackets refer to notes of the Crisis Management Manual $^{38}$ as shown in the second column of this figure.
Corresponding notes to be shown on the reverse side SCAN

(1) Circulation: Note the volume of the pulse. The $\mathrm{ETCO}_{2}$ is used here as an index of venous return and cardiac output.

(2) Oxygen: If the source is not via an anaesthetic machine (e.g. direct supply from wall outlet, cylinder or oxygen concentrator), check the flowmeter and the integrity of supply from source to patient.

(3) Endotracheal tube: At insertion note and chart the distance marker at the teeth or gums when the tip is $3 \mathrm{~cm}$ (in an adult) past the vocal cords. Check this distance against the charted value, especially after the patient has been moved, the surgeon is working near the tube, or hammering or manipulation has taken place. If an LMA is in use, distance checks do not apply.

(4) Review Monitors: Note that all sensors are correctly placed, zeroed and levelled where appropriate, and note that they have been calibrated, if this is possible and practical. Note that alarm and alert settings are appropriate and are turned on.

(5) Review Equipment: Review all equipment in use by yourself and the surgical team including diathermy, endoscopes, probes, retractors, heating blankets, humidifiers etc. Ensure that no physical, thermal or chemical damage can be done to the patient, and that the equipment is functioning as expected.

(6) Airway: Note any inappropriate use or pattern of the accessory muscles of respiration, any excessive retraction of the trachea or thyroid, and any uncoordinated or paradoxical movements of the chest or abdomen in relation to respiratory efforts.

(7) Circulation: In estimating blood or other fluid loss, suction bottle contents, swabs, drapes and floor should be checked. Remember that blood can pool under the patient on the table, and that considerable bleeding can take place into tissue spaces and body cavities. Note that venous return can be substantially influenced by retraction, pressure by the surgeon, by the gravid uterus lying on the inferior vena cava, or by manipulation of the heart, lungs or great vessels. Also, remember that traction, especially on the eye muscles and peritoneum, can cause vagal stimulation.

(8) Drugs: Note that all syringes or infusions have been labelled in a standardised manner with the generic name of the drug (or fluid) and the dose (in $\mathrm{mg} / \mathrm{ml}$ ), and that the ampoules from which the ingredients have been taken are available for checking. Note that all IV lines are secure, and, if possible, visible from source to patient entry site.

(9) A: Always consider these possibilities; each made up about $1 \%$ of AIMS reports.
A SWIFT CHECK stand for (Michael Burt, personal communication). Each $\mathbf{A}$ in this sentence acts as a reminder for two things: Awareness in the patient and as an exhortation to the anaesthetist to be Aware; Air for Air (and other) embolism and for Air in the pleural space (pneumothorax); and Allergy to act as a reminder for Allergic reactions and Anaphylaxis (see table 3).

Secondly, it was suggested that the SWIFT CHECK should now be taken simply as a reminder for a swift check during the normal 5 minute scan "of the surgeons', assistants', nurses' and orderlies' activities and of the operative site, a quick consideration of the pattern of physiological change revealed by the monitors, and a mental review of the patient's history and preoperative status" ${ }^{4}$ The conditions listed under SWIFT CHECK in table 2 have been dealt with in some of the companion papers (see asterisks in table 3 ) and in some additional algorithms in the Crisis Management Manual. $^{38}$ 
The column on the left lists, in the order of the mnemonic, what should be "checked". This will comprise a "facing" page of the manual. Notes corresponding to the numbers in parentheses will be on the reverse side.

\section{CHECK: whenever you are worried}

Circulation: Palpate a pulse. Correlate rate, rhythm and volume with the oximeter and ECG. Check capillary refill and $\mathrm{ETCO}_{2}$ trace (1).

Colour: If suspicious try the pulse oximeter on yourself. Take arterial blood for a lab check on saturation or blood gases.

Oxygen: Briefly increase the oxygen flow rate and calculate the new expected $\mathrm{FIO}_{2}$ in the breathing circuit.

Oxygen Analyser: Check that the changes in the $\mathrm{FIO}_{2}$ are in line with the calculated changes in $\mathrm{FIO}_{2}$ in the breathing circuit.

Ventilation: Ventilate by hand. Check circuit, scavenging, valves and visible moving ventilator parts.

Vaporisers: Check the vaporiser(s) are correctly seated and set, "locked in" and connected and that there are no gas or liquid leaks.

Endotracheal tube or laryngeal mask airway: Check position, orientation and patency. If ET tube is in use exclude endobronchial intubation (2).

Eliminate: Check that an independent means of ventilating the patient (e.g. self-inflating bag) and an alternate supply of oxygen are available.

Review monitors: Check all monitors in use and compare current monitor values with those on the anaesthetic record (3).

Review equipment: Check that all equipment in contact with or relevant to the patient is safe and functioning correctly.

Airway: Observe, palpate and auscultate the neck. If suspicious of airway obstruction, plan direct pharyngoscopy.

Breathing: Palpate and auscultate the chest whilst repeating SCAN. Review the $\mathrm{ETCO}_{2}$ if a capnograph is in use.

Circulation: Cross check any abnormal BP readings where possible. Check the zero and scales of transducers.

Drugs: Check all ampoules, syringes, labels, infusion apparatus, connections \& cannulae from fluid source to vein (4).

A: Specifically consider the possibility of Awareness (5), Air (or other) embolism (6), Air in pleura (pneumothorax) (7), Allergy or Anaphylaxis (8). See the relevant sub-algorithms for signs and high risk situations.

SWIFT CHECK: Correlate the monitored parameters with the clinical situation and risk factors. Specifically question the surgeon about what is being done, and check the pre-operative assessment, medical record and ward drug chart.
Corresponding notes to be shown on the reverse side

\section{CHECK}

(1) Circulation: If possible, manually check a pulse other than the one being sensed by the oximeter. Beware - some oximeters automatically increase the size of the plethysmograph trace, if its volume is small.

(2) Endotracheal tube: Endobronchial intubation must always be excluded. Palpation of the pilot balloon while squeezing the cuff in the trachea above the sternal notch will confirm its position, and slight withdrawal may also resolve desaturation. Patency: Ventilate the tube directly (remove circuit, filter, connections) with a separate system (see Eliminate). The tip of the tube may have moved, the lumen become obstructed or the cuff herniated into the lumen or over the end of the tube. If there is any suspicion of regurgitation, aspiration or obstruction of a tube, perform direct laryngoscopy, suck out the pharynx, adjust the tube's position, consider adjusting the cuff and pass a suction catheter through the tube. Don't forget swabs or packs.

(3) Review monitors: Always attempt to confirm correct siting, calibration, alarm settings and function:

Oximeter: Check the probe on yourself, try another site, try another probe, try another oximeter.

Capnograph: Breathe into the sensor yourself and check that the $\mathrm{ETCO}_{2}$ reads $5 \%$ or $40 \mathrm{~mm} \mathrm{Hg}$. Remember, a sudden fall in $\mathrm{ETCO}_{2}$ may be due to entrainment of room air between the gas sampling site and the capnograph.

Blood pressure: Confirm automated noninvasive blood pressure measurements manually before acting. Check zero and calibration of direct measurements.

ECG: Check the right leads are in use, that waveforms are calibrated and that the monitor is in diagnostic mode before assessing ST segments.

(4) Drugs: Consider whether the problem might be the result of failure of drug delivery or the wrong drug, wrong dose, wrong route, or wrong time of administration being used.

(5) Awareness: Consider previous drug/alcohol use. Look for signs of sympathetic activity. Check the anaesthetic is actually being delivered. If in doubt, deepen anaesthesia.

(6) Air (and other) embolism: Always consider with a fall in $\mathrm{ETCO}_{2}$ desaturation, hypotension and/or a sudden change in ECG rate or configuration, especially in a risky situation.

(7) Air in pleura (pneumothorax): If cardio-respiratory compromise remains undiagnosed after COVER ABCD, expose the chest and abdomen, and carefully compare left and right sides, using inspection, palpation and auscultation.

(8) Allergy or anaphylaxis: Look for hypotension, a fall in $\mathrm{ETCO}_{2}$ bronchospasm, desaturation and skin signs.

Figure 4 Items which, in the order of the mnemonic, should be CHECKED.

\section{DEVELOPMENT OF THE SUB-ALGORITHMS}

Following analysis of the first 2000 reports as described in the 1993 symposium issue, ${ }^{34}$ the need for a number of specific sub-algorithms was identified to assist the anaesthetist in treating the remaining $40 \%$ of the incidents that were not corrected by the COVER core algorithm. Volunteer anaesthetists were given sets of incident reports from the first 4000 AIMS reports that dealt with the specific clinical problems shown in table 3 . These sets were generated by using the key word section on the AIMS form. For incidents that involved large numbers of reports (such as airway obstruction and desaturation), at least two anaesthetists were involved in the initial data analysis while for those where there were fewer reports (such as water intoxication) one investigator initially reviewed the data. As the majority of reported cases were clearly dealt with well, the reporting anaesthetists' described actions played an important role in creating the crisis management sub-algorithms. Each sub-algorithm was 
The column on the left lists, in the order of the mnemonic, what should be done in the ALERT/READY phase. This will comprise a "facing" page of the manual. Notes corresponding to the numbers in parentheses will be on the reverse side.

\section{ALERT/READY Call for help/trolleys $(1,2)$}

Circulation: If there is an impending arrest allocate the "circulation" task (1) and ask for the arrest trolley to be fetched.

Colour: If the oximeter is suspect, resite or replace it and/or do an arterial blood gas. Consider inserting an arterial line.

Oxygen: If adequate saturation cannot be confirmed, administer $100 \%$ oxygen. Plan how to provide analgesia and anaesthesia.

Oxygen Analyser: Confirm that the gas in the inspired limb of the breathing circuit is $100 \%$ oxygen.

Ventilation: Allocate the "airway and breathing" task (1). Ventilate with a self-inflating bag. See breathing below.

Vaporisers: Turn the vaporiser off if there is cardiorespiratory compromise. Plan how to provide analgesia and anaesthesia.

Endotracheal tube or laryngeal mask airway: Allocate the "equipment" task (1). If suspicious, prepare to remove and change the tube or LMA.

Eliminate: Prepare and check the correct function of an alternate breathing system and separate oxygen source.

Review monitors: Recheck, correlate and record all readouts and trends. Call for additional monitors as necessary.

Review equipment: Remove or replace suspect equipment. Bring in additional emergency equipment as appropriate.

Airway: Adjust head and neck, attempt gentle chin lift. Prepare for pharyngoscopy; if suspicious, go to airway obstruction.

Breathing: Expose the chest and abdomen. Repeat SCAN and CHECK whilst comparing $L$ and $R$ sides. Consider causes.

Circulation: Check IV access. Secure additional access (venous and arterial) as necessary. Prepare to transfuse.

Drugs: Allocate the "drugs" task (1). Check all drugs and infusions and the entire IV apparatus. Draw up, check and label drugs that may be needed.

A: Decide whether Awareness, Air (or other) embolism, Air in pleura (pneumothorax), Allergy and Anaphylaxis are possible causes of the problem, and act accordingly (see algorithms).

SWIFT CHECK: Make another assessment of the general situation of the patient, of the activities of the surgeon and other personnel, and of the possible effects of the operation and/or any drugs or infusions.

\section{Corresponding notes to be shown on the reverse side.}

\section{ALERT/READY}

\section{(1) Call for Help - Allocate Tasks}

TASKS: Airway (A), Breathing (B), Circulation (C), Drugs (D), Equipment (E).

PERSON 1: Initially the anaesthesiologist - to look after A, B, overall coordination and cycling through COVER and the appropriate algorithm/s. When skilled assistance is available the anaesthesiologist may delegate $A, B$, and concentrate on coordinating activities and checking algorithms.

PERSON 2: The anaesthetic assistant. This person should be primarily responsible for $\mathrm{D}, \mathrm{E}$, although may be deployed by the anaesthesiologist to other tasks.

PERSON 3: This person should look after $C$. If there is a cardiac arrest, this person should be responsible for ECM.

PERSON 4: To be deployed by the anaesthesiologist. If there is a cardiac arrest, this should be the second person looking after $C$, ensuring good intravenous access, injection of intravenous drugs, and ensuring they are flushed through.

PERSON 5: This person and any other available person should be deployed by the anaesthesiologist. It is most important that each person be given a specific task, e.g. "Can you independently assess the situation, go through COVER and sub-algorithms $X$ and $Y$, and check that all is going to plan"? OR "Please help the anaesthetic assistant getting drug Z ready", OR "Please help Person 3 (or 4) get the defibrillator ready".

\section{(2) Emergency Equipment and Drug Trolleys}

Standard sets of equipment and drugs should be available on trolleys which can be brought in, or in drawers on the anaesthetic machine. The following should be available:

Airway Equipment I (Standard)

Airway Equipment II (Difficult intubation)

Breathing Equipment I (Standard)

Breathing Equipment II (Pleural drainage/bronchoscopy)

Circulatory Equipment I (Standard)

Circulatory Equipment II (Cardiac arrest)

Drugs - Emergency I (Standard)

Drugs - Emergency II (For unusual problems)

Equipment Extras I (Spare set of monitors)

Equipment Extras II (For unusual problems)

Figure 5 Items which, in the order of the mnemonic, should be done in the ALERT/READY phase.

developed by those who had reviewed the reports and by at least one other specialist with a clinical interest in that area. Once a sub-algorithm had been created, the relevant analysts again reviewed each of the reports in the relevant set. The potential value of using a structured approach-that is, the application of COVER ABCD-A SWIFT CHECK to the diagnosis and initial management of each problem-followed by the application of the sub-algorithm for that specific problem was assessed in the light of each of the relevant
AIMS reports from the first 4000. This was done by comparing the potential effectiveness of the structured approach for each incident with that of the actual management, as recorded in each report. A judgement was made by the reviewers as to whether the sub-algorithm, properly applied, would have led to a better or quicker resolution of the problem, and specific consideration was also given to whether use of the sub-algorithm could have caused a problem. Other relevant aspects of the incidents were 
The column on the left lists, in the order of the mnemonic, what should be done in the EMERGENCY phase. This will comprise a "facing" page of the manual. Notes corresponding to the numbers in parentheses will be on the reverse side.

\section{EMERGENCY}

Do not hesitate to declare an emergency.

Allocate tasks, get trolleys (see facing page)

Circulation: If the pulse of $\mathrm{ETCO}_{2}$ fails, feel for a major pulse and start external cardiac massage (1)

Colour: If there is any question of cardiac, circulatory or respiratory compromise, give $100 \% \mathrm{O}_{2}$ regardless of the saturation.

Oxygen: Supply $100 \%$ oxygen at a very high flow rate if necessary.

Oxygen analyser: Confirm the inspired gas in the breathing circuit is $100 \%$ oxygen.

Ventilation: Ventilate by hand - use a self-inflating bag. Obtain appropriate chest movement, airway pressures and $\mathrm{ETCO}_{2}$ (see breathing below).

Vaporisers: Turn off all vaporisers unless the problem is clearly unrelated or is hypertension or awareness.

Endotracheal tube or laryngeal mask airway: Remove and replace if there is any doubt whatsoever about its position or patency.

Eliminate: The machine, circuit, filter and connections unless the problem is clearly unrelated.

Review monitors: Frequently scan. Allocate someone to review trends and keep notes and ensure sensor integrity.

Review equipment: Check, and remove all non-essential equipment in contact with patient (retractors, diathermy, etc).

Airway: Go to laryngospasm, airway obstruction, or aspiration algorithms as indicated. Consider intubation.

Breathing: Go to bronchospasm, pulmonary oedema, ARDS, ventilation, desaturation algorithms as indicated. Consider ventilation.

Circulation: Go to tachycardia, bradycardia, hypotension, hypertension, myocardial ischaemia, or cardiac arrest.

Drugs: Has there been an error? Ensure all drugs are labelled and keep a record of doses and times.

A: Go to awareness, air (and other) embolism, air in pleura (pneumothorax) and anaphylaxis algorithms as indicated.

SWIFT CHECK: Go through as indicated when there is time.
Corresponding notes to be shown on the reverse side

CARDIAC ARREST - Also see page 38*

\section{COORDINATION}

Ensure people are allocated to tasks A, B, Cl (external cardiac massage), C2 (IV access and feeling the pulse), D and E (see page 9*). As soon as possible, ensure that COVER, the cardiac arrest algorithm and any other relevant algorithms are cycled through (page 38*).

\section{ENSURE CONTINUOUS BASIC LIFE SUPPORT}

External cardiac massage (ECM) at 80-100 per minute Confirm a major (preferably femoral) pulse can be felt

Ventilate with $100 \%$ oxygen every fifth ECM

Confirm that ventilation is adequate (inspect, auscultate)

Minimise interruptions during therapeutic manoeuvres.

EMERGENCY MANAGEMENT

Follow the 2000 ILCOR ACLS Guidelines

VF or pulseless VT

Defibrillate with $200 \mathrm{~J}, 200-300 \mathrm{~J}$ then $360 \mathrm{~J}$ as needed

If VT/VF continues (vasopressin 40 iu once or adrenaline $1 \mathrm{mg}$

q 3-5 $\mathrm{min}$ )

Defibrillate at $360 \mathrm{~J} \mathrm{q} 60 \mathrm{~s}$

Refractory cases consider amiodarone $(4-5 \mathrm{mg} / \mathrm{kg})$, lignocaine

$(1 \mathrm{mg} / \mathrm{kg})$, magnesium $(0.1 \mathrm{mmol} / \mathrm{kg})$ and procainamide $(20$

$\mathrm{mg} / \mathrm{min}$ up to $1000 \mathrm{mg}$ )

Asystole

Give adrenaline by IV bolus - $1 \mathrm{mg}$ for an adult $\mathrm{q} 3-5 \mathrm{~min}$ (i.e. about $0.15 \mu \mathrm{g} / \mathrm{kg}$ )

Consider atropine $1 \mathrm{mg} \mathrm{IV}$, up to $0.04 \mathrm{mg} / \mathrm{kg}$

Consider cardiac pacing

Pulseless Electrical Activity (PEA)

Give adrenaline by IV bolus $-1 \mathrm{mg}$ for an adult q $3-5 \mathrm{~min}$ (i.e. about $0.15 \mu \mathrm{g} / \mathrm{kg}$

Consider atropine $1 \mathrm{mg} \mathrm{IV}$, up to $0.04 \mathrm{mg} / \mathrm{kg}$

Consider causes; hypovolaemia, hypoxia, hypo and hyperkalaemia, hypothermia, hydrogen ion acidosis, tablets (OD), tension pneumothorax, thrombosis (coronary and pulmonary embolism), cardiac tamponade

Basic life support should be continued until return of spontaneous circulation. Also see page $38^{*}$.

NOTE: Calcium chloride $10 \%(5-10 \mathrm{ml}$ in an adult) should only be used for hyperkalaemia, hypocalcaemia, or an overdose of calcium channel blockers.

NOTE: Sodium bicarbonate is not recommended (1 mg/kg IV) by the Australian Resuscitation Council and American Heart Association. There is no evidence for any benefit and considerable experimental evidence that it may be harmful.

NOTE: There is evidence that dextrose containing solutions may be harmful after a cardiac arrest.

*Page references refer to the Crisis Management Manual. ${ }^{38}$

Figure 6 Items which, in the order of the mnemonic, should be done in the emergency phase

tabulated. A paper was then written for each sub-algorithm outlining the background to the subject, with a description of the methods and the results of the evaluation for each subalgorithm. These papers make up the rest of this set of 25 articles. ${ }^{9-32}$

Fourteen sub-algorithms for the ABCD portion of the mnemonic were developed and checked against the relevan incidents among the first 4000 reported to AIMS. Four were developed and checked for the four "As" of A SWIFT CHECK and six for aspects of SWIFT CHECK (see table 3). These subalgorithms were then compiled as the original Crisis Management Manual. ${ }^{38}$

\section{THE CRISIS MANAGEMENT MANUAL}

The original Crisis Management Manual was developed as a 74 page document. ${ }^{38}$ Two thousand copies of this draft manual were distributed at the 1996 Scientific Congress of the World Federation of Societies of Anaesthesiologists held in Sydney, Australia. Comments and feedback were sought from those to whom the manuscript was delivered. These comments were then incorporated, wherever relevant, into the crisis management sub-algorithms. The refined subalgorithms which resulted are shown in this set of 24 articles.

Each of these forms the basis for a page in the Crisis Management Manual. In the hard copy version of the 
manual there are easy-to-use tabs down the right hand sides of the pages to allow the anaesthetist immediate access to sub-algorithms for problems with non-specific cues such as desaturation, but which also allow direct access to subalgorithms for specific problems such as anaphylaxis or air embolism, when these are immediately recognised. There are also tabs at the tops of the first few pages for rapid access to the SCARE sequences.

An electronic copy of the algorithms in the manual was made available on the internet. ${ }^{38}$ Unlike paper manuals, these web based manuals are more flexible and allow rapid updates to all users. With the more frequent use of personal computers and hand held devices, it was felt that this would be a beneficial medium in which to house the manual. To this end, an electronic software form of the manual has been developed using hypertext documentation that can be used on a personal computer or a hand held personal desk assistant (e.g. Palm Pilot ${ }^{\mathrm{TM}}$ ). The program uses frames with resizable boxes and scroll bars on the sides. Underlined text expands into full text boxes and, within the crisis algorithm itself, collapsible headings and hyperlinks and pop-up boxes are used to fully describe each of the sub-algorithms. The personal computer program is of most use as a teaching tool, while the ease of use and instant availability of a hand held device allows the manual to be instantly accessible during times of a crisis. This version is currently being used by some trainee anaesthetists in New Zealand (Charles Bradfield, personal communication).

\section{COMMENTS ON THE CRISIS MANAGEMENT MANUAL}

Since the publication of the core algorithm, five meetings on crisis management have been held: one at Noosa in Queensland in June 1993; one at Toukley in New South Wales in March 1994; and two 2 day meetings in association with Annual Scientific Meetings of the Australian Society of Anaesthetists, one in Fiji in November 1994 and one in Melbourne in October 1995. Finally, the electronic version was demonstrated at the 2001 Annual Scientific Meeting of the Australian Society of Anaesthetists in Canberra. The 2001 Canberra meeting was especially important as it was the first meeting for several years following dissemination of the draft manual. At all of these meetings the sub-algorithms presented in this issue were presented, discussed, and refined. It was recognised that the methods used for "validating" the algorithms were intrinsically limited and subject to "hindsight bias". Prospective validation using simulation would be ideal but will require a large scale, carefully designed study.

It was agreed by all that the algorithms should only be used when the usual responses based on pattern recognition do not appear to have been successful. Also, right from the start it was agreed that the use of the traditional cardiac arrest mnemonic "ABCD" was too limited for more complex problems which arise because of the interposition of artificial gas supplies, anaesthetic machines (with additional hazards such as vaporisers), artificial airways, and various breathing circuits with failure prone components such as one-way valves and arrangements for carbon dioxide absorption. For example, hypoxic gas mixtures (especially $100 \%$ nitrous oxide), potentially fatal vapour concentrations, and circuit "over-pressures" must be excluded almost immediately or severe patient harm or death may ensue rapidly. A number of additional important points were raised at the various meetings.

Firstly, it is important to recognise that the AIMS reports simply constitute a body of information arising from occasions when anaesthetists were sufficiently interested or concerned by an event to report it and the surrounding circumstances as an incident. It is known that common or mundane events are under-reported-for example, circuit disconnections and leaks are under-reported but are nevertheless the most frequently reported incidents-whereas very dramatic and unusual events are more likely to be reportedfor example, anaphylactic reactions or air embolism. ${ }^{41}{ }^{42}$

The relative frequencies with which various types of incident are reported thus provide some hybrid reflection of the relative frequency with which they occur and the degree of interest or alarm they engender. Although reporting such comparative frequencies may produce considerable unease in classical epidemiologists, it does have practical relevance to a body of anaesthetists who are provided with a prioritised catalogue of events sequenced according to their perceived relative importance by fellow practitioners. ${ }^{39}$ Half of New Zealand anaesthetists who responded to a survey $(57 \%$ response rate) felt that AIMS had changed their practice. ${ }^{43}$

The second issue addressed was whether the AIMS data are relevant to crises that actually have adverse outcomes. Data from anaesthetic deaths which were substantially attributed to anaesthetic management and which occurred within 48 hours of anaesthesia in the UK (790 deaths) and New South Wales (172 deaths) indicate that the AIMS data are relevant. ${ }^{39}{ }^{44}$ In $80 \%$ of the deaths on the same day the first sign of disaster was a life threatening crisis. Of all these crises leading to death, three quarters are in the AIMS "top $10^{\prime \prime}$ and nearly all the remainder are in the next $10 .{ }^{39}$ There is also a striking similarity between the presenting signs in the UK and New South Wales studies (table 4); ${ }^{44}$ the nonspecificity of these signs confirms that a structured approach would be desirable as there was a large number of causes of the underlying problems.

In the UK study $30 \%$ of deaths were in patients who were ASA grade 1-4 and in the New South Wales study $40 \%$ of deaths were in patients regarded as being "fair risks". The conclusions that AIMS crises are relevant for validating crisis management algorithms, that many crises which result in death start with non-specific signs, and that problems may arise in low or moderate risk patients all support the routine use of a structured algorithm. Studies from elsewhere have confirmed that there is a strong association between "initial process events" and poor outcomes. ${ }^{45} 46$

The third problem which arose for discussion was that, even if structured algorithms are available, poor team work may compromise their execution. Again, the ideal is that practising anaesthetists should undergo regular simulation sessions in which they play various roles in crisis situationsthat is, the equivalent of cockpit resource management sessions in the aviation industry. ${ }^{47-49}$ However, in reality this will not be possible for all anaesthetists in the near future. Experience from attending real crises and from observing Australian anaesthetists in simulated crisis situations-for example, during the crisis management simulation session in Toukley, New South Wales in March 1994-confirms that teamwork is often poor. The use of a crisis management

Table 4 Comparison of mode of presentation of 360 NCEPOD* and $138 \mathrm{NSW}^{* *}$ crises $^{44}$

\begin{tabular}{lcc}
\hline Incident & NCEPOD & NSW \\
\hline Hypotension & $33 \%$ & $43 \%$ \\
Cardiac arrest & $24 \%$ & $25 \%$ \\
Arrhythmia & $19 \%$ & $24 \%$ \\
Cyanosis & $7 \%$ & $6 \%$ \\
Pulmonary oedema & $3 \%$ & $3 \%$ \\
\hline
\end{tabular}

*Data from the National Confidential Enquiry into Perioperative Deaths (UK).

**Data from the New South Wales Special Committee Investigating

Deaths under Anaesthesia (Australia). 
manual allows a coordinating person (usually an anaesthetist) to allocate tasks for individual members of the operating room team. In this way, tasks will be prioritised and it will be ensured that the essential basic tasks are carried out in the correct sequence and in an expeditious manner. The value of a crew resource management approach cannot be overemphasised and its introduction into clinical practice needs to be widely supported. ${ }^{2}{ }^{49}$ Better communication was cited by over two-thirds of operating room nurses and doctors as the most important intervention required to improve safety, ${ }^{49}$ underlining the importance of moving towards formal team training using simulators.

This may be based on the use of crisis management algorithms which, in the future, may be available as part of the software of integrated monitoring devices and clinical decision support systems. The first step was producing Palm and PC-based versions of this crisis management manual. The introduction of such an approach into commercial monitoring systems has gained interest by some manufacturers and is well recognised as being an effective way of applying information of this sort..$^{50} 51$

Fourthly, the use of COVER ABCD-A SWIFT CHECK and the sub-algorithms does not guarantee a good outcomemerely that an appropriate sequence of actions will have been carried out in the vast majority of cases. In some instances something will have been done (such as a wrong drug given) or something will have occurred (such as pulmonary embolism) that has consequences that the anaesthetist cannot reverse or even control. Also, it is inevitable that the "core" algorithm and sub-algorithms will not always be correctly applied. However, if this is the case, as long as these are available in an easy-to-access form, others called to assist in the management of an escalating crisis will have a fresh chance of resolving the problem.

The sub-algorithms have been designed to be a simple set of instructions that can be followed in an emergency. It is inevitable that these algorithms will differ from "accepted practice" in some regions and do not represent the only acceptable course of action. However, it is suggested that they be followed in crises when pattern recognition has failed, at least in the first instance, as they have been designed to represent appropriate courses of action in the vast majority of circumstances. If this structured approach proves to be unhelpful, the anaesthetist can always revert to problem solving from "first principles". The relevant sub-algorithm should also be examined following resolution of an incident to ensure that the reason for the crisis has not been missed and to facilitate appropriate ongoing care and management. Although the structured approach advocated may not be the best for every situation, it will be consistent, is unlikely to harm the patient, will assist in the diagnosis of the problem in $99 \%$ of cases, and will be better than the current clinical management by the average clinician in at least one in eight incidents.

Finally, crisis management is not complete until the consequences for the patient, his or her friends and relatives, all medical (and other) staff involved, and the implications for the institution, practice or system have been dealt with. ${ }^{52}$ An approach to this is outlined in the final paper in this set of $\operatorname{articles}^{32}$ and forms the last section of the Crisis Management Manual. ${ }^{38}$ An "open disclosure" standard has now been developed by the Australian Council for Safety and Quality in Health Care which supplements the approach advocated in this last section of the manual. ${ }^{53}$

The sub-algorithms presented in this set of 24 articles were developed as an adjunct for the practising clinician to use in the resolution of incidents that occur during anaesthesia. They are didactic but are open to debate, discussion, and criticism. They form the basis of what we believe to be a

\section{Key messages}

- This paper forms the introduction to a set of 24 articles that outline a structured approach for use when things go wrong during anaesthesia. Prevention is not the intent of this set of articles as the focus is on crisis management.

- From three meetings involving 60-100 anaesthetists it was agreed that a "core" crisis management algorithm was needed when either cause or response to treatment during an anaesthesia crisis was not apparent.

- From the study of the first 4000 incidents reported to AIMS, a need for 24 specific sub-algorithms was identified based on successful strategies identified in the reports.

- Using the application of the previously reported core algorithm, the 24 sub-algorithms were assembled in a user friendly manual for trial against the 4000 incident reports.

- The trial showed that this structured approach would aid in diagnosis in $99 \%$ of crises and would provide better management than that of the average clinician, without patient harm, in one in eight of the situations.

- Poor teamwork may compromise the execution of a structured algorithm.

- These algorithms will differ from "accepted practice" in some regions and do not represent the only acceptable course of action.

- Such structured approaches lend themselves readily to simulation training in anaesthesia, resuscitation, and intensive care.

useful step in developing a rational evidence-based approach to crisis management during anaesthesia. However, much remains to be done. The COVER component has been found to be satisfactory in real life resuscitation situations. ${ }^{54}$ Carefully designed simulator based studies, using naïve trainees right at the start of training, could evaluate the approach advocated here against possible alternatives, and could systematically examine the merits and demerits of various aspects of the sub-algorithms and how they are presented. The extent to which "pre-compiled responses" should be required to be used-as in aviation and by the policies of some hospitals with respect to the use of cardiac arrest protocols-is likely to be the subject of lively debate as medical practice receives increased scrutiny. Due to the complexities of clinical medicine, however, it would seem prudent, for the foreseeable future, that the "core algorithm" and "sub-algorithms" described in this set of articles be regarded as "decision aids" to support and back up a clinicians' natural responses to a crisis when all is not progressing as expected. ${ }^{55}$

\section{ACKNOWLEDGEMENTS}

The authors would like to thank all the anaesthetists in Australia and New Zealand who contributed to the 4000 incident reports upon which this and the other 24 papers in the Crisis Management Series are based. The coordinators of the project also thank Liz Brown for preparing the draft of the original Crisis Management Manual; Loretta Smyth for typing; Monika Bullock RN for earlier coding and classifying of data; Dr Charles Bradfield for the electronic version of the algorithms; Dr Klee Benveniste for literature research; and Drs Klee Benveniste, Michal Kluger, John Williamson and Andrew Paix for editing and checking manuscripts. 


\section{Authors' affiliations}

W B Runciman, Professor and Head, Department of Anaesthesia and Intensive Care, University of Adelaide and Royal Adelaide Hospital, Adelaide, South Australia, Australia

M T Kluger, Senior Staff Specialist, Department of Anaesthesiology and Perioperative Medicine, North Shore Hospital, Auckland, New Zealand R W Morris, Director, Research and Development, Sydney Medical Simulation Centre, Royal North Shore Hospital, St Leonards, New South Wales, Australia

A D Paix, Consultant Anaesthetist, Princess Royal University Hospital, Orpington, Kent, UK

L M Watterson, Senior Staff Specialist and Director, Sydney Medical Simulation Centre, Royal North Shore Hospital, St Leonards, New South Wales, Australia

R K Webb, Senior Staff Specialist, Department of Anaesthesia and Intensive Care, The Townsville Hospital, Douglas, Queensland, Australia This study was coordinated by The Australian Patient Safety Foundation, GPO Box 400, Adelaide, South Australia 5001, Australia.

\section{REFERENCES}

1 Runciman WB. Crisis management. Anaesth Intensive Care 1988;16:86-8.

2 Gaba D, Fish K, Howard S. Crisis management in anesthesiology. New York: Churchill Livingstone, 1994

3 Fisher MMcD, ed. The anaesthetic crisis. Best Pract Res Clin Anaesthesiol 1993:7:199-515

4 Runciman WB, Webb RK, Klepper ID, et al. Crisis management: validation of an algorithm by analysis of 2000 incident reports. Anaesth Intensive Care 1993;21:579-92.

5 Merry A, McCall Smith A. Errors, medicine and the law. Cambridge: Cambridge University Press, 2001:19-22.

6 Kohn LT, Corrigan JM, Donaldson MS, eds. To err is human: building a safer health system. Washington, DC: National Academy Press, 1999.

7 Department of Health. An organisation with a memory. Report of an expert group on learning from adverse events in the NHS, chaired by the Chief Medical Officer. London: The Stationery Office, 2000.

8 Runciman WB, Moller J. latrogenic injury in Australia. Adelaide: Australian Patient Safety Foundation, 2001.

9 Visvanathan T, Kluger MT, Webb RK, et al. Crisis management during anaesthesia: obstruction of the natural airway. Qual Saf Health Care 2005; 14:e2.

10 Visvanathan T, Kluger MT, Webb RK, et al. Crisis management during anaesthesia: laryngospasm. Qual Saf Health Care 2005;14:e3.

11 Kluger MT, Visvanathan T, Myburgh JA, et al. Crisis management during anaesthesia: regurgitation, vomiting, and aspiration. Qual Saf Health Care 2005; 14:e4.

12 Paix AD, Williamson JA, Runciman WB. Crisis management during anaesthesia: difficult intubation. Qual Saf Health Care 2005;14:05.

13 Szekely SM, Runciman WB, Webb RK, et al. Crisis management during anaesthesia: desaturation. Qual Saf Health Care 2005;14:e6.

14 Westhorpe RN, Ludbrook GL, Helps SC. Crisis management during anaesthesia: bronchospasm. Qual Saf Health Care 2005;14:e7.

15 Chapman MJ, Myburgh JA, Kluger MT, et al. Crisis management during anaesthesia: pulmonary oedema. Qual Saf Health Care 2005; 14:e8.

16 Watterson LM, Morris RW, Westhorpe RN, et al. Crisis management during anaesthesia: bradycardia. Qual Saf Health Care 2005; 14:e9.

17 Watterson LM, Morris RW, Williamson JA, et al. Crisis management during anaesthesia: tachycardia. Qual Saf Health Care 2005; 14:e10.

18 Morris RW, Watterson LM, Westhorpe RN, et al. Crisis management during anaesthesia: hypotension. Qual Saf Health Care 2005;14:e11

19 Paix AD, Runciman WB, Horan BF, et al. Crisis management during anaesthesia: hypertension. Qual Saf Health Care 2005; 14:e12.

20 Ludbrook GL, Webb RK, Currie M, et al. Crisis management during anaesthesia: myocardial ischaemia and infarction. Qual Saf Health Care 2005; 14:e13

21 Runciman WB, Morris RW, Watterson LM, et al. Crisis management during anaesthesia: cardiac arrest. Qual Saf Health Care 2005;14:e14.

22 Paix AD, Bullock MF, Runciman WB, et al. Crisis management during anaesthesia: problems associated with drug administration during anaesthesia. Qual Saf Health Care 2005; 14:e15.
23 Osborne GA, Bacon AK, Runciman WB et al. Crisis management during anaesthesia: awareness. Qual Saf Health Care 2005;14:e16.

24 Williamson JA, Helps SC, Westhorpe RN, et al. Crisis management during anaesthesia: embolism. Qual Saf Health Care 2005;14:e17.

25 Bacon AK, Paix AD, Williamson JA, et al. Crisis management during anaesthesia: pneumothorax. Qual Saf Health Care 2005; 14:e18.

26 Currie M, Kerridge RK, Bacon AK, et al. Crisis management during anaesthesia: anaphylaxis and allergy. Qual Saf Health Care 2005;14:e19.

27 Singleton RJ, Kinnear S, Currie $M$, et al. Crisis management during anaesthesia: vascular access problems. Qual Saf Health Care 2005; 14:e20.

28 Griggs WM, Morris RW, Runciman WB, et al. Trauma: development of a subalgorithm. Qual Saf Health Care 2005;14:e21

29 Myburgh JA, Chapman MJ, Szekely SM, et al. Crisis management during anaesthesia: sepsis. Qual Saf Health Care 2005; 14:e22.

30 Kluger MT, Szekely SM, Singleton RJ, et al. Crisis management during anaesthesia: water intoxication. Qual Saf Health Care 2005;14:e23.

31 Fox MAL, Morris RW, Runciman WB, et al. Crisis management during regional anaesthesia. Qual Saf Health Care 2005;14:e24.

32 Bacon AK, Morris RW, Runciman WB, et al. Crisis management during anaesthesia: recovering from a crisis. Qual Saf Health Care 2005; 14:e25.

33 Webb RK, Currie M, Morgan C, et al. The Australian Incident Monitoring Study: an analysis of 2000 incident reports. Anaesth Intensive Care 1993;21:520-8.

34 Australian Incident Monitoring Study. Symposium: The Australian Incident Monitoring Study. Anaesth Intensive Care 1993;21:501-695.

35 Runciman WB, Merry AF. Crisis management in clinical care: an approach to management. Qual Saf Health Care 2005;14:156-63.

36 Reason JT. Human error. New York: Cambridge University Press, 1990.

37 Nolan TW. System changes to improve patient safety. BMJ 2000;320:771-3.

38 Australian Patient Safety Foundation. Crisis Management Manual: COVER $A B C D$ A SWIFT CHECK. Adelaide: Australian Patient Safety Foundation, 1996, $74 \mathrm{pp}$. Also available online at http://www.apsf.net.au/ anaesthesia.htm (accessed 6 September 2004).

39 Webb RK, van der Walt JH, Runciman WB, et al. Which monitor? An analysis of 2000 incident reports. Anaesth Intensive Care 1993;21:529-42.

40 Runciman WB, Webb RK, Barker L, et al. The pulse oximeter: applications and limitations - an analysis of 2000 incident reports. Anaesth Intensive Care 1993;21:543-50.

41 Gaba DM. Anaesthesiology as a model for patient safety in health care. BMJ 2000;320:785-8

42 Flanagan JC. The critical incident technique. Psychol Bull 1954;51:327-8

43 Yong $\mathrm{H}$, Kluger MT. Incident reporting in anaesthesia: a survey of practice in New Zealand. Anaesth Intensive Care 2003;31:555-9.

44 Warden JC, Lunn JN. The role of anaesthesia in death. Best Pract Res Clin Anaesthesiol 1993;7:199-214.

45 Boelle PY, Garnerin P, Sicard JF, et al. Voluntary reporting system in anaesthesia: is there a link between undesirable and critical events? Qual Health Care 2000:9:203-9.

46 Katz RI, Lagasse RS. Factors influencing the reporting of adverse perioperative outcomes to a quality management program. Anesth Analg 2000;90:344-50.

47 Caro PW. Flight training and simulation. In: Wiener EL, Nagel DC, eds. Human factors in aviation. San Diego: Academic Press, 1988:229-62.

48 Gaba DM, De Anda A. The response of anaesthesia trainees to simulated critical incidents. Anesth Analg 1989;68:444-51.

49 Helmreich RL, Schaefer HG. Team performance in the operating room. In: Bognor MS, ed. Human error in medicine. Hillside, NJ: Erlbaum, 1994:225-53.

50 Schneider AJ, Murray WB, Mentzer SC, et al. "Helper": a critical events prompter for unexpected emergencies. J Clin Monit 1995;1 1:358-64.

51 Bent PD, Bolsin SN, Creati BJ, et al. Professional monitoring and critical incident reporting using personal digital assistants. Med J Aust 2003; 178:359

52 Bacon AK. Major anaesthetic mishaps - handling the aftermath. Curr Anaesth Crit Care 1990;1:253-7.

53 Australian Society for Safety and Quality in Health Care. Open disclosure standard: a national standard for open communication in public and private hospitals, following an adverse event in health care. Canberra: Australian Council for Safety and Quality in Health Care, 2003. Available from: http:// www.safetyandquality.org/articles/Publications/OpenDisclosure web.pdf (accessed 15 December 2004).

54 Jaberi M, Xiao Y, MacKenzie CF, et al. Incident monitoring by videotaping of acute trauma patient management. Anesthesiology 1996;85(3A):A1036.

55 Klein G, Orasanu J, Calderwood R, et al. eds. Decision making in action: models and methods. Norwood, NJ: Ablex Publishing Corporation, 1993. 